\title{
Mostrar un milagro. El caso de La Guadalupana y la Nueva Basílica
}

\section{Showing a Miracle. The Case of La Guadalupana and the New Basilica}

\author{
Sergio Isaac Porcayo Camargo \\ Facultad de Filosofía y Letras, UNAM. México DF, México. \\ isaac.porcayo@comunidad.unam.mx
}

\section{Resumen}

La tradición cultual mexicana alrededor de la imagen de la Virgen del Tepeyac se ha estudiado insistentemente por su importancia para el surgimiento del nacionalismo criollo, pero se ha ignorado la pervivencia del culto en el México contemporáneo, resultado de un programa visual particular. La construcción de la identidad mediante prácticas relativas a imágenes "milagrosas" funciona actualmente gracias a tecnologías que renuevan el despliegue icónico. Entender su funcionamiento original ayuda a entender su pervivencia hasta nuestros días. En este ensayo se aborda este problema mediante el análisis de la creación de un nuevo sitio expositivo para la Virgen del Tepeyac (Nueva Basílica), así como las modalidades de reproducción de la imagen. Comparar visualmente estas técnicas contemporáneas de mostración y reproducción con las del siglo xVIII, permitirá atisbar la coherencia y el sentido de esta tradición visual y su importancia para la construcción de los procesos sociales en México.

Palabras clave: guadalupanismo, tecnología visual, imagen, mirada, economía escópica.

\section{Abstract}

The Mexican cult around the image of the Virgin of Tepeyac is commonly addressed in relation with creole nationalism, but that emphasis ignores the survival of its cult until today. Given that construction of identity through 'miraculous' images persists through technologies of iconic deployment, it is necessary to examine the original functions of its technologies. I investigate these problems by considering the construction of a new exhibition site for the Virgin of Tepeyac (New Basilica), and the modalities of reproducing the image until today. The historical comparison of these contemporary techniques with those of the seventeenth century enables to appreciate the coherence of this visual tradition and its importance to the construction of social processes in Mexico.

Keywords: guadalupanismo, visual technology, reception, image, gaze, scopic economy. 


\section{Introducción}

En 1976 se terminó la Nueva Basílica que albergaría la célebre imagen de la Virgen del Tepeyac, de base circular y sin pilastras que sostuvieran la techumbre. La justificación para levantar esta edificación era que la afluencia de peregrinos volvía insegura la basílica del siglo XviII, al pie del cerro del Tepeyac, donde se dice que se apareció la virgen. La narración de 1535, el Nican Mopohua (“Aquí se cuenta”, en náhuatl), relata las apariciones de la Virgen a un campesino llamado Juan Diego, quien debía pedirle al obispo Zumárraga un templo, "una casita". Desde entonces se harían muchos templos en diversos estilos, de los cuales el último es la Nueva Basílica.

El fenómeno guadalupano está ligado a la construcción. Parece que, además de los argumentos de seguridad y de la necesidad de acoger a los peregrinos que arriban para la fiesta del 12 de diciembre, el proyecto de la Nueva Basílica de 1976 repite el gesto fundacional que motiva la narración: la búsqueda de esa "casita" que pedía la Virgen al obispo.

Parece tratarse de un hecho fundamental, de otro modo la imagen no se habría estampado en la tilma. Existe, entonces, una circularidad estructural en la narración del Nican: a) la virgen quiere un templo; b) el obispo no cree a su mensajero; c) entonces ella se estampa en su tilma, ${ }^{1}$ imagen sin la cual el templo que pedía la guadalupana habría estado vacío.

En este orden de ideas, la construcción de la Nueva Basílica parece tener implicaciones profundas; parte de una necesidad mucho más significativa que los argumentos técnicos. Se trata de una herencia histórica bastante arraigada, dado que la historia del culto guadalupano siempre tuvo como asunto la importancia simbólica de la edificación; pero también, como argumentaré más adelante, la reproducción de imágenes. Estas son las prácticas clave que hay que estudiar para comprender la pervivencia de las imágenes "milagrosas" en nuestra cultura. En específico, desarrollaré el caso mexicano en las páginas siguientes, desde una visión histórica y filosófica para encontrar su relevancia social desde el punto de vista de los estudios visuales. Ciertamente, existen otra serie de prácticas que se deben dilucidar pragmática y simbólicamente: la elaboración de pinturas populares, el papel de la imprenta y las procesiones, son elementos que hay que estudiar. Sin embargo, en esta ocasión me centré en los fenómenos constructivos y copísticos dada su cercanía con un programa institucional, que revela de forma más adecuada los códigos propios que lo inscribieron en lo que se ha llamado "conciencia nacional".

Sin duda, el guadalupanismo es uno de los fenómenos sociales de mayor raigambre en México. Se trata de un fenómeno social fuertemente vinculado a tecnologías

1 Tilma: vestido mexicano de estilo de manto o capa de la época. En este caso en particular, también puede ser llamado ayate, en referencia a las fibras con que es hilado. 
FIGURA 1

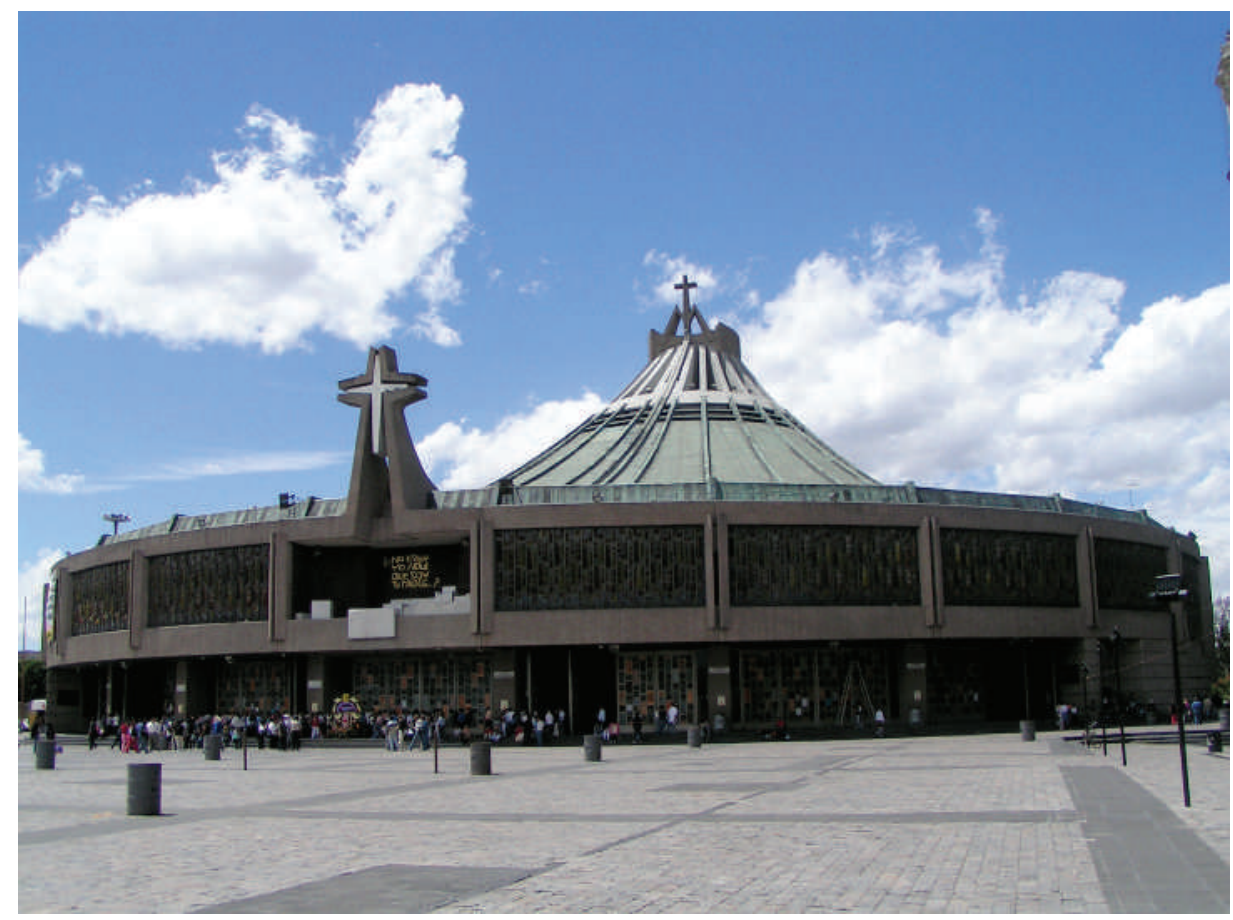

Nueva Basílica. México, 1976.

de despliegue visual, no únicamente a la creencia en el "portentoso estampamiento" que narra Nican. De ahí surge la importancia de plantear la problemática que supone esta tradición en su complejidad visual.

Conviene mencionar brevemente una serie de problemas que marcarán el fenómeno de la realización de copias y los fenómenos constructivos. El principal es la definición misma de la imagen para los autores que van del siglo XVII al XVIII. Si bien es imposible abarcar toda una pléyade de autores -o criticarlos a todos- no se debe olvidar la importancia de la conceptualización contemporánea a los fenómenos que se analizarán. Miguel Sánchez es el autor más importante y prácticamente el iniciador de una serie de textos teológicos acerca de la imagen de la virgen. Sánchez no se limitó a realizar una historia de la imagen y de sus milagros, sino que construyó una compleja lectura teológica basada en el estudio de las tipologías. Según Sánchez, la imagen de María de México habría estado contenida ya en el antiguo testamento y su sentido profético se encontraría también en la historia de los antiguos mexicanos. De ese modo, el autor prolonga el sentido doctrinal de la teología de la imagen formulado anteriormente, señalando al icono mexicano como una imagen generada por el poder de Dios, y no de la misma virgen. Así, señala la Aprobación de Juan de Poblete a su libro que: "resplandece más bien el poder infinito de Dios, que con un fiat de su dezir, 
que es obrar, saca a la luz un orbe todo: que mucho que al desplegar unas flores, saque estampada una imagen de su Madre santísima milagrosa!” (Sánchez II s/p).

Este sentido teológico parece ser la interpretación dominante de otros autores, aunque entre los llamados "evangelistas" por Francisco de la Maza, existan algunas diferencias. Tal es el caso de Lasso de la Vega, quien escribe en el Huey tlamahuizoltica que: "de modo milagroso entregó su preciosa imagen, que no pintó ningún pintor de este mundo, porque ella misma se retrató, queriendo amorosamente estar allí asentada" (Lasso de la Vega 87). ${ }^{2}$ Sin embargo, esta interpretación no parece haber llegado al siglo xvin, salvo en el escrito Felicidad de México de Tanco. De allí que sea necesario tener en cuenta esta divergencia, pero dando por hegemónica la lectura de Sánchez en razón de una continuidad con la historia de la imagen en Europa. Según Sánchez, la pintura fue hecha por Dios, mientras que, para Lasso de la Vega, no solo es acheropoietos, sino que la hizo ella misma, para "estar allí asentada". Estas dos concepciones parecen resumirse en dos maneras de reproducir la imagen: una como imagen pintada y otra como ícono reproducible; es decir, la historia visual se decanta por la segunda manera.

La lectura de Sánchez parece haber fomentado las características de la tradición visual que se presenta en los siguientes apartados en sus manifestaciones de reproducción y constructivos, dado que su tipología y su lectura profética evidencian un mensaje oculto, un misterio que contiene la imagen. Aunque la experimentación visual se adelanta a la teología -el libro de Sánchez data de 1648, mientras la copia de la virgen más antigua está fechada en 1606-, es gracias a esta lectura que se realiza durante el siglo XVIII una exhaustiva codificación de la imagen, así como la mostración cada vez más espectacular del ícono.

\section{La vieja basílica}

El edificio hoy conocido oficialmente como Templo Expiatorio a Cristo Rey tuvo una resonancia especial para la sociedad novohispana, que pretendía dignificar el culto guadalupano, al mismo tiempo que dignificaba toda la Nueva España. Así es como se ha señalado, sobre todo a partir de representaciones pictóricas, que el templo es una sinécdoque de la Nueva España (Cuesta 130), que se proyectó como una Nueva Jerusalén, o al menos así lo comprendieron algunos coetáneos el diseño original de José Durán.

Sin duda era osado trazar una planta basilical para el templo inaugurado en 1709, que además estaba dedicado a un culto oficialmente menor, ya que hasta 1754 no se efectuaría la declaración pontificia del patronato de la Virgen de Guadalupe sobre la

2 Esta obra es una compilación de textos en lengua náhuatl que contiene el texto mencionado de narraciones aparicionistas, Nican Mopohua. 
FIGURA 1

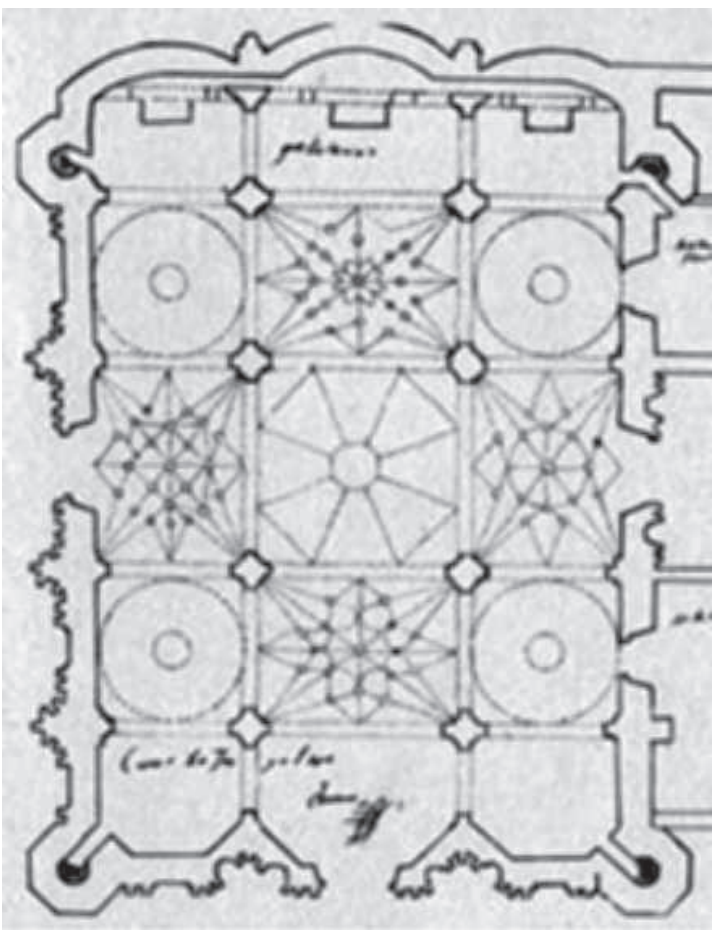

José Durán. Plano de la Planta de la Basílica de Guadalupe. Archivo de Indias, Sevilla, 1694.

Nueva España. Este diseño parece hablar de ambiciones y sueños de una sociedad que comenzaba a cansarse de que las decisiones importantes se tomaran más allá de sus fronteras, en la península. De algún modo, este templo canalizaría ese cansancio mediante una exigencia de relevancia.

Esta es una de las lecturas que se han realizado desde la historia del arte. No obstante, aunque resulta de gran relevancia el estudio del nacionalismo y la conciencia criolla, me gustaría centrarme en otros aspectos concernientes a la vivencia de este templo; además de su carácter de dispositivo de despliegue icónico cuya tecnología visual -al ser la última "casita" de la Virgen hasta la segunda mitad del siglo xx- nunca estuvo del todo lograda. ${ }^{3}$

3 Utilizo el concepto tecnología visual, dispositivo, y régimen escópico en una lectura híbrida de la teoría de Michel Foucault, como se ha realizado en los estudios visuales, sobre todo en el texto de Martin Jay “¿Parresía Visual? Foucault y la verdad de la mirada" y en "Campos de fuerza. Entre la historia intelectual la crítica cultural". Sin embargo, sustituyo la palabra régimen usada por Jay por la de economía, dado que no se trata de un conjunto de reglas claras que determinan la visualidad, sino la modalidad de circulación visual de la imagen determinada por su exponibilidad en el caso del original, y por su frecuencia visual en el caso de las copias. Por otra parte, el concepto de mirada barroca sí está influido por el planteamiento de régimen escópico, siendo, para Jay, el modelo barroco uno de los más importantes en la modernidad. 


\section{FIGURA 3}

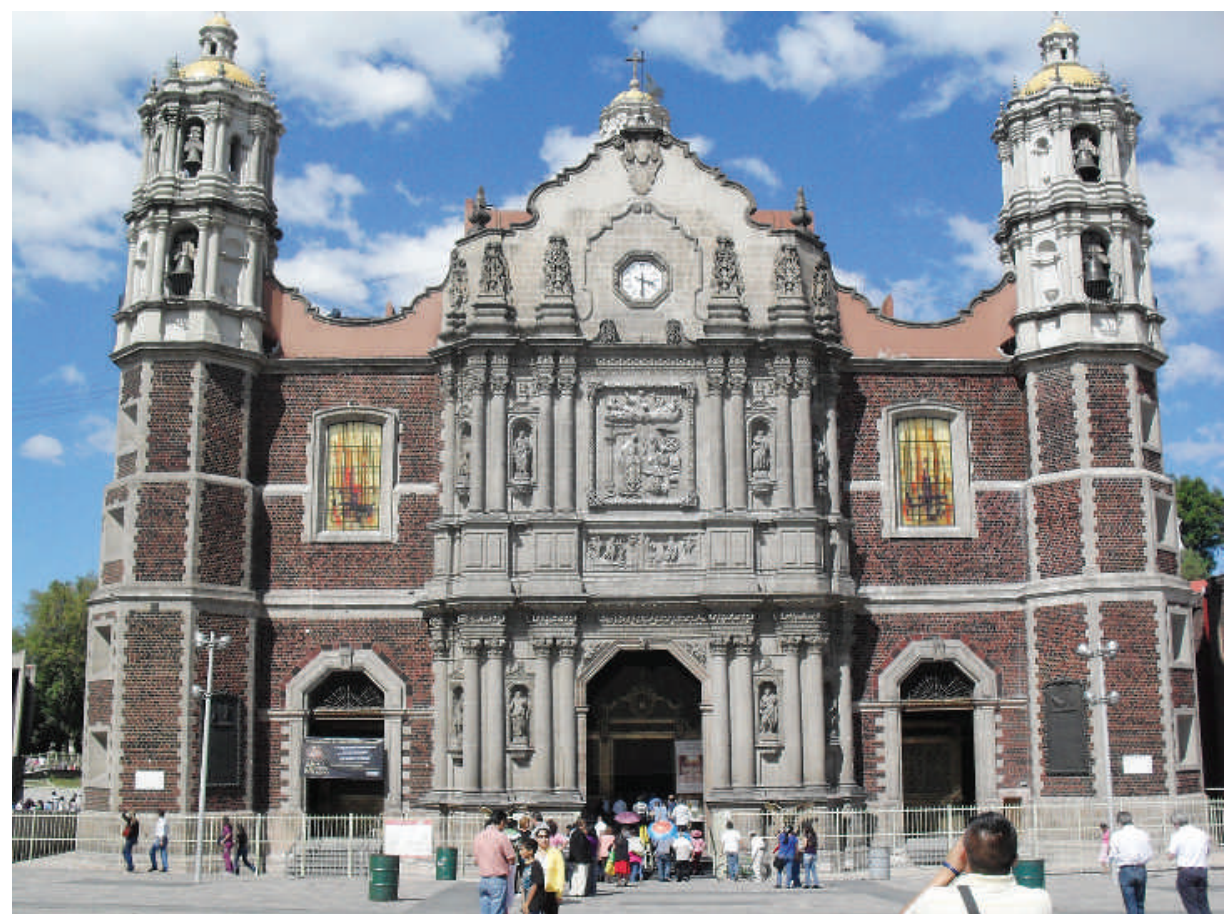

Conjunto Villa de Guadalupe. México, 2008.

La fastuosidad del templo autorizaba de hecho la narración milagrosa que sustentaba la devoción por la imagen. En una sociedad tan dada a los deslizamientos alegóricos de significado, la masividad y autoridad se trasladaban a la imagen.

Es posible asegurar que el culto tuvo que ser construido a base de templos -entre muchas otras actividades de promoción eclesiástica, como señala pertinentemente Camacho de la Torre, entre ellas la formación de patronatos-, que ascendería a tres entre1556 y el siglo XVIII. La autoridad de estas imágenes era acentuada por el hecho de que no se encontraban disponibles en todo momento, sino que se hallaban cubiertas, resguardadas de las miradas, y se descubrían a vista del público solo en ciertas ocasiones (De Florencia 101). De allí que el tratamiento expositivo haya sido más bien el de una reliquia portentosa; más parecido al del Manto de Turín, que al de una imagen protectora.

El misterio que bañaba su exposición litúrgica tenía su contrapunto en ocasiones festivas, cuyo objetivo era -como hoy en día- mostrar la imagen para rendir culto. Estas prácticas se regulaban a partir de una economía escópica de rarefacción o despliegue limitado, lo cual se aprecia en las copias de la época que, como explicaré más adelante, tenían la dificultad de establecer el estatus de la imagen original. Por ello las representaciones son variadas $y$, en cierto sentido, experimentales. 
FIGURA 4

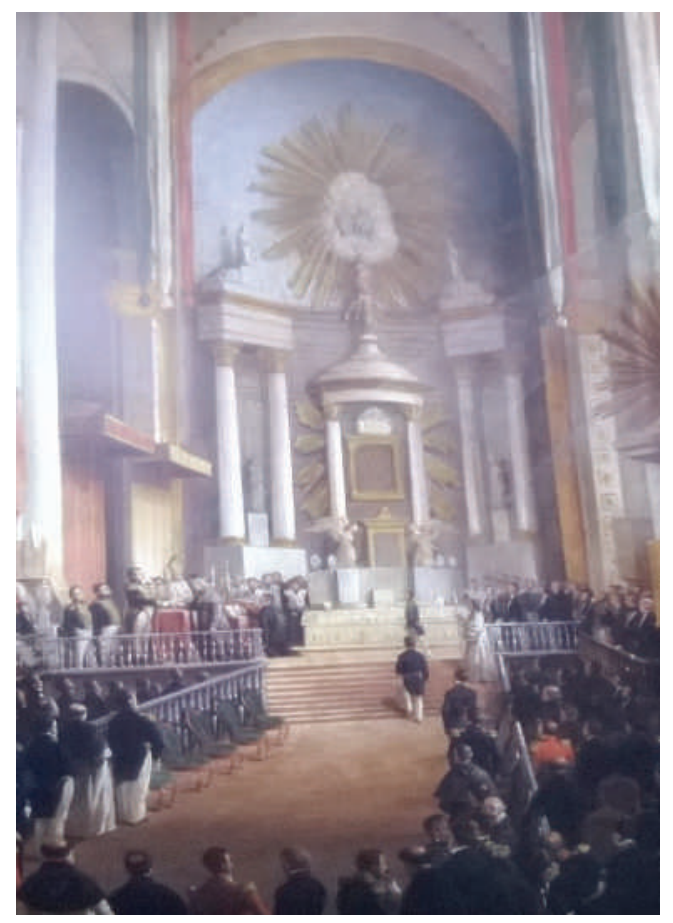

Pingret Édourad. Reinstalación de la Orden de Guadalupe en la Colegiata de Guadalupe. Óleo sobre lienzo. Museo Nacional de Historia. México, 1854.

Sin embargo, la necesidad de difusión y engrandecimiento de la imagen conllevó el cambio de su estatus de reliquia al de imagen omnipresente. Hubo muchos problemas en el siglo XVII para definir el carácter objetivo de la tilma. Incluso los principales tratadistas hicieron un esfuerzo para definirla como una pintura divina, similar a la Virgen de Santa María Maggiore, mucho más maravillosa, ya que según Tanco sería la misma imprimación por los rayos del sol sobre la tela. Por tanto, la Virgen del Tepeyac sería, en cierto sentido, la Virgen misma (De la Maza 111).

Poco a poco este parecer imperaría. De ese modo, el tratamiento visual que se daría a la virgen, sería algo más sistematizado. Esto se manifiesta en el hecho de que las copias de la virgen ya no cambiarían demasiado desde finales del siglo XVIII hasta el siglo xx. Luego, la tecnificación digital revolucionaría completamente el fenómeno de su reproducción.

Es importante señalar, con respecto al templo, que las remodelaciones subsiguientes avanzarían, además de a una renovación hacia la búsqueda de un aumento de la exposición, la cual, al mismo tiempo, constituiría una búsqueda de engrandecimiento y de significación de la imagen. La sustitución de un altar barroco por uno neoclásico en 1802 -dirigida por Manuel Tolsá, aunque interrumpida por la guerra de independencia- implica ya un síntoma del cambio de economía escópica, dejando 


\section{FIGURA 5}

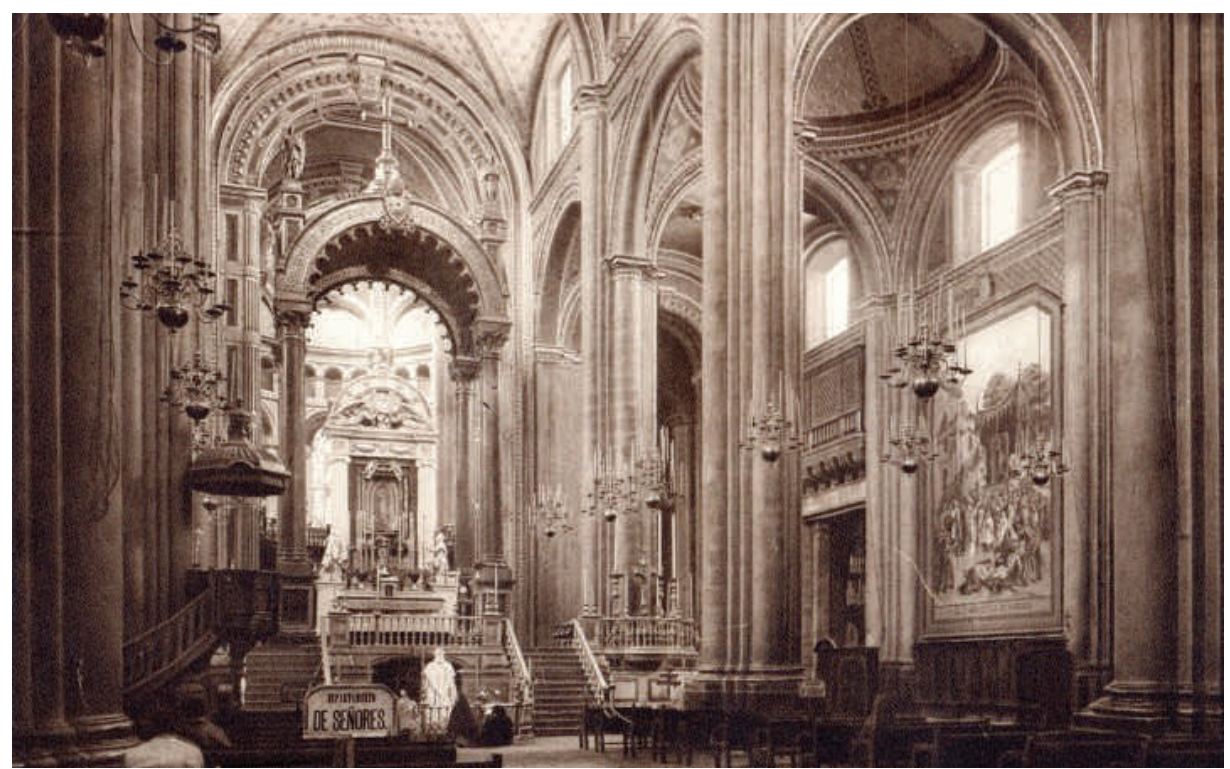

Hugo Brehme. Interior de la Basílica de Guadalupe. Gelatina de plata. Sistema Nacional de Fototecas. México, 1920.

atrás la mistérica economía de rarefacción para alcanzar la economía de proliferación. En una pintura de Édouard Pingret (activo en México de 1850 a 1855) se observa que la imagen se encuentra disponible a la vista tras una vidriera.

Posteriormente, en 1895, para celebrar la coronación de la virgen concedida por León XIII, se cambió el altar por un baldaquino, además de la ampliación de la nave. Nuevamente, y esta vez mucho más ambiciosamente, el aumento de las dignidades de La Guadalupana se corresponden con una puesta al día en las tecnologías visuales, que ahora, en un régimen de proliferación, buscan el alcance visual de la virgen.

Estos cambios tendrían implicaciones sociales variadas, ya que la constante exposición de los fieles a la imagen acentuaría el sentimiento nacionalista criollo de que eran un pueblo elegido, que incluso se apropiaría sin pudor de la frase emitida por Benedicto XIV “non fecit taliter omni nationi”.

\section{La Nueva Basílica}

Hasta ahora he esbozado solamente ciertas manifestaciones visuales del culto de la Virgen del Tepeyac. Las limitaciones son múltiples, la información escasa; pero, como sostenía desde el principio, creo que la construcción de la Basílica de 1976 debe analizarse no solo desde las raíces históricas del culto, sino también en una historia de sus tecnologías visuales. 
FIGURA 6

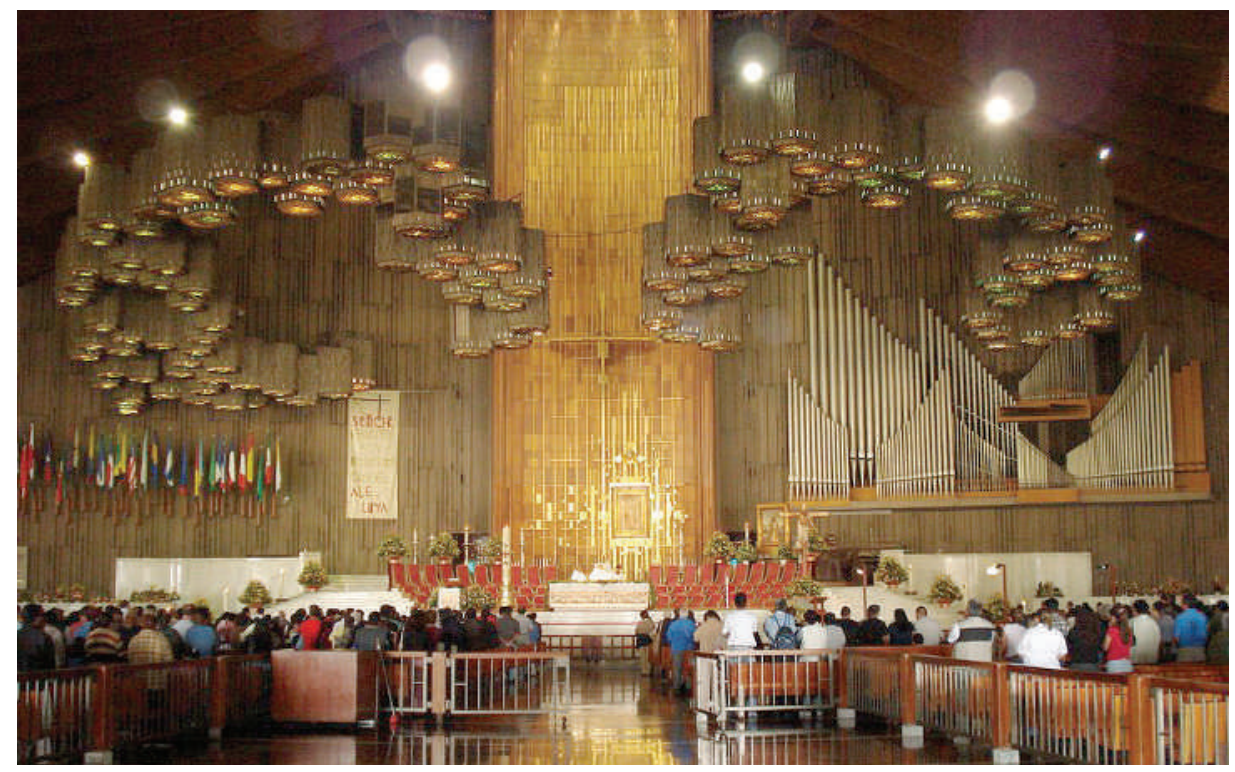

Interior de la Nueva Basílica. Fotografía digital, 2017.

Más que heredera directa de las retóricas barrocas, la efectividad expositiva parece obedecer a la consolidación de un régimen de proliferación regulado institucionalmente, que busca no ya un gobierno de la imagen, no su administración, sino su omnipresencia; el grado máximo de exhibición buscaría naturalmente un despliegue absoluto o al menos más perfecto del que permitía la basílica del siglo xvir. En este caso, se confirma que la visualidad del fenómeno trasciende las diferencias de los estilos artísticos.

Es posible interpretar el proyecto dirigido por Pedro Ramírez Vázquez como el último paso en la búsqueda por satisfacer las necesidades de un culto donde la visualidad era vital. El moderno templo circular goza de una "vista radial, es decir que el lienzo original de Guadalupe puede ser visto desde cualquier punto del edificio en que se coloque el visitante" (Martínez 194). Sin embargo, la imagen se encuentra ligeramente descentrada, lo que amplía el espacio frontal por donde se accede. Otra de las características de este espacio es que el retablo dorado también facilita la visibilidad de la imagen, dado que es de una sencillez extrema, con volúmenes poligonales sobresalientes y sin un patrón evidente; presenta los visos luminosos de un retablo estofado, pero sin distraer la atención del ícono central, el único.

La iluminación, como en las iglesias góticas y barrocas, es fundamental. Como es previsible, recae sobre la imagen, confiriéndole una nueva aura sobrenatural. $\mathrm{Me}$ parece posible resaltar un nuevo emparentamiento con el templo gótico: en este caso, la innovación es una especie de modernización del deambulatorio que, en la Edad Media, permitía a los peregrinos recorrer las capillas de la iglesia sin interrumpir la 
celebración de la misa. En el caso de la Nueva Basílica se trata de una banda mecanizada que, a la inversa, pasea a los peregrinos por debajo de la imagen. Esto ocurre durante treinta segundos, tiempo que, según dicen, es el que lleva rezar un Ave María. Es posible que este recurso funcione como una forma de animación de la imagen, dado que el espectador se desplaza debajo de ella sin esfuerzo físico. Ello además refuerza la centralidad de la imagen. Mediante esta disposición, después de 256 años de estar colocada en la Antigua Basílica, la imagen renovó todo su marco visual, proceso por el cual logró asumir la omnipresencia icónica que, desde el siglo XVIII, se acariciaba, pero cuyas tecnologías visuales no habían logrado concretizar.

Siguiendo esta línea de la historia de las tecnologías visuales que rodean a la imagen, es posible detectar la continuidad visual operante a lo largo del siglo $\mathrm{xx} \mathrm{y}$ XxI: el despliegue de la imagen es omnipresente, aunque ello también implica, con la agilidad visual que caracteriza a nuestro siglo, que los significados atribuidos a la virgen se han multiplicado desde su estabilización en el siglo xviII. A partir de ello parece posible afirmar que la tecnología visual solo alcanza los ideales del siglo XVII en el siglo $\mathrm{xx}$.

\section{Copias de ayer, réplicas de hoy}

El proceso de estabilización de la imagen se llevó a cabo gracias a las copias. Es imposible hacer una revisión de todas las copias que se han hecho de la Virgen del Tepeyac. Lo que resulta central en este proyecto es detectar la correspondencia entre los modos de representar la imagen y la transformación de los regímenes escópicos; es decir, rastrear los medios reproductivos por los que La Guadalupana llegó a ser una imagen omnipresente.

En primer lugar, el abordaje de las maneras en que se realizaban copias de la imagen, ayuda a definir la importancia particular de tal actividad: un ensayo cultural de la época por definir la naturaleza o el estatus del objeto ante el que se encontraban. Las primeras copias eran más bien intentos no muy bien logrados, sobre todo si se considera que no tenían acceso directo para hacer una copia fiel. Esto bajo lo que he llamado economía de rarefacción. Sin embargo, hay pinturas que constituyen una excepción, siendo de una gran calidad. Echave Orio hizo una pintura en gran formato. Pero esta no se trata de una copia en sentido estricto, dado que hizo una representación de la imagen de la tilma donde se estampó la virgen. En este caso en particular, se aprecia la filiación a la comprensión de la tilma como una antigüedad, por ello la pintura de Echave tendría menos un sentido milagroso que un sentido didáctico.

Es interesante comprobar que esta representación -la más antigua de la que se tenga constancia (1606) - sea anterior a los textos que relanzaron el guadalupanismo a mitad del siglo xviI. Los refuerzos textuales vinieron quizá algo tarde, con el libro de Miguel Sánchez, Imagen de la Virgen María, madre de Dios de Guadalupe, en 1648, 
FIGURA 7

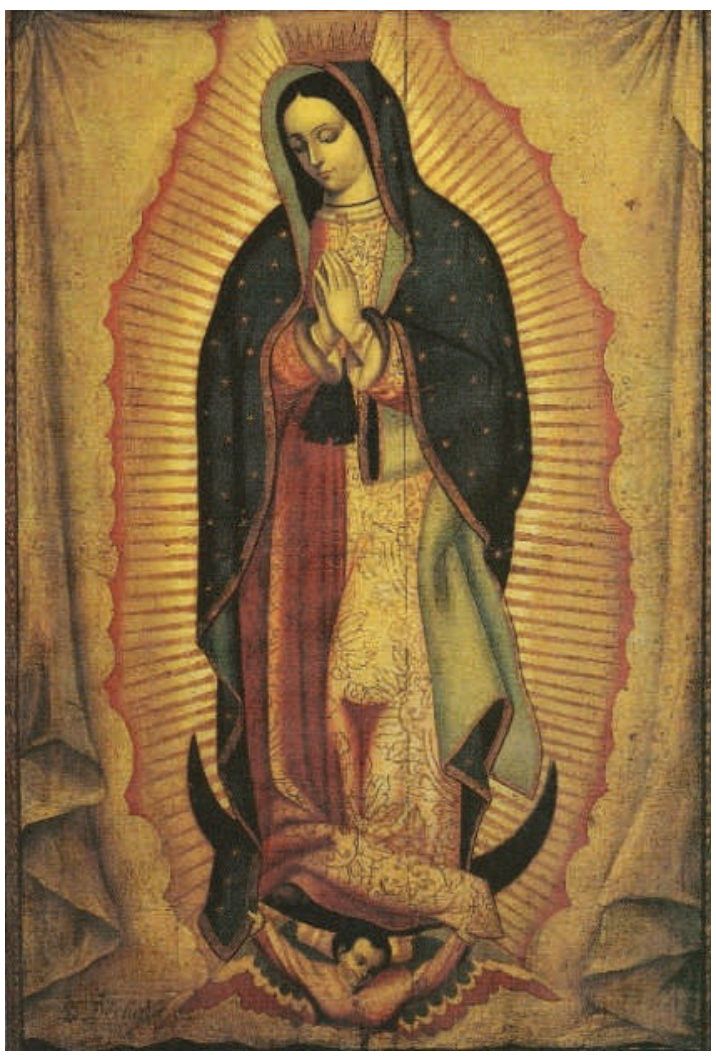

Baltasar de Echave Orio. Virgen de Guadalupe. Óleo sobre lienzo. Colección Particular. México, 1606.

después de una serie de abandonos y recuperaciones del culto durante la colonia (Gruzinski 122).

Lo mismo ocurre con una pintura temprana, de 1625, realizada por Delapyedra, que opta "como la mayoría de los pintores coloniales" por la solución icónica (Vargas 61). Estas dos soluciones pictóricas son experimentadas tempranamente, decantándose la tendencia copística por sobre la segunda, solución icónica. Sin duda, era más fácil de adaptar a un proceso temprano de tecnificación; pero más allá de ello, se insertaba en un programa visual ya teorizado por teólogos como Sánchez.

El libro de Sánchez es posterior a la experimentación pictórica que resultaba tan importante para determinar la jerarquía del original, pero parece haber fijado el camino de las copias que ya había sido probado. ¿Por qué, entonces, es tan común decir que los hagiógrafos de la imagen prácticamente definieron el carácter del culto? Aunque su importancia cultural sea crucial, ¿no existe una cultura visual que hablaría de un ensayo anterior a esas definiciones teológicas?

El estudio de los hagiógrafos es necesario para entender ciertos movimientos culturales, ya que en muchos sentidos ellos encaminaron el culto. Sánchez establece 


\section{FIGURA 8}

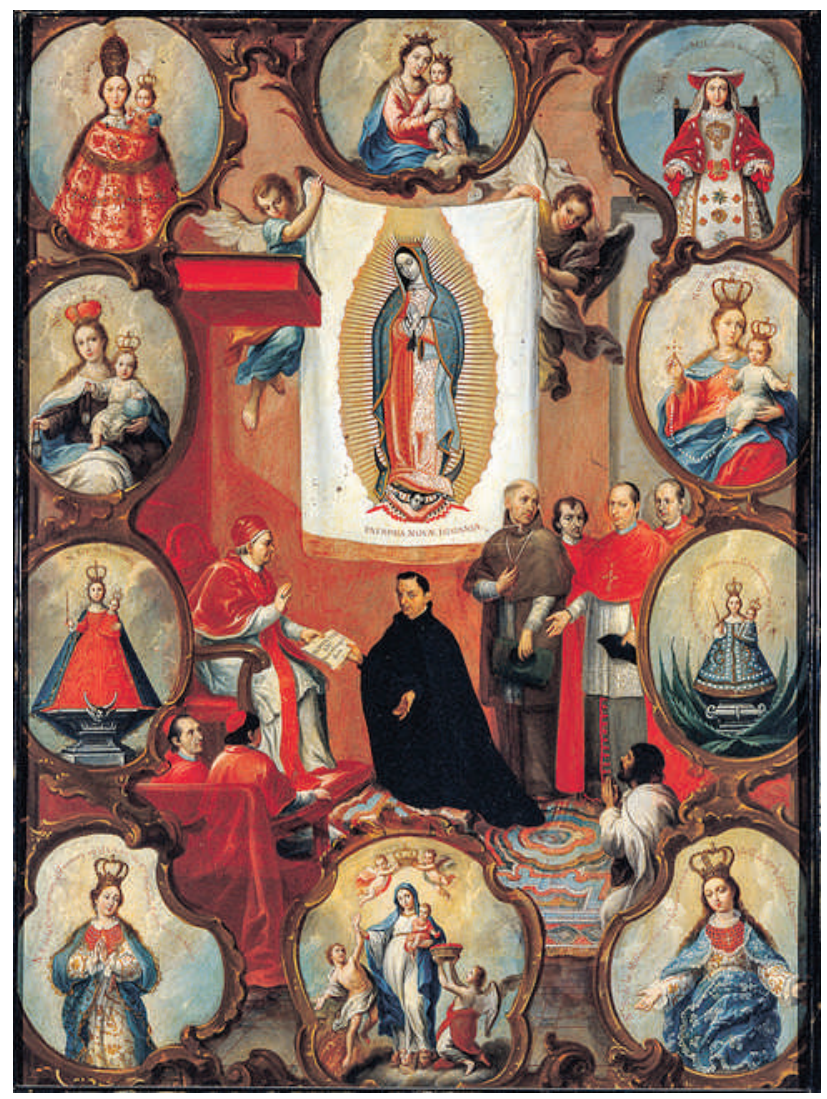

Miguel Cabrera (atribuido). Proclamación pontificia del Patronato de la Virgen de Guadalupe sobre el Reyno de la Nueva España. Óleo sobre lámina de cobre. Museo Soumaya. México, Circa, 1754.

dos conceptos que resultan culturalmente fundamentales en la definición de la imagen: a) recupera la autoridad del acheropoietos; b) establece mediante una interpretación tipológica, el concepto de Signum. Esto último tiene un sentido profético que influirá la tradición visual, que si bien no está del todo determinada por las definiciones, tampoco es independiente.

¿La noción de revelación fue decisiva al momento de realizar las copias de la virgen del Tepeyac? La reproducción de la imagen, después de los primeros experimentos pictóricos, se realizó de una manera especial y distinta, de alguna manera tecnificada, lo que garantizaba el parecido "exacto" al original. Esta práctica, que involucra de manera especial al pintor Miguel Cabrera -aunque no únicamente- se explica por varios factores institucionales y sociales, pero también doctrinales. Si el pintor Juan Correa hizo un calco de la imagen alrededor de 1650, dos años después de la aparición del texto de Sánchez -hecho ya de por sí interesante-, el gesto de calcar una imagen de esta categoría cobra sentido en la práctica de Miguel Cabrera. Cabrera funge como el transmisor de ese mensaje establecido por Sánchez, y esa co- 
FIGURA 9

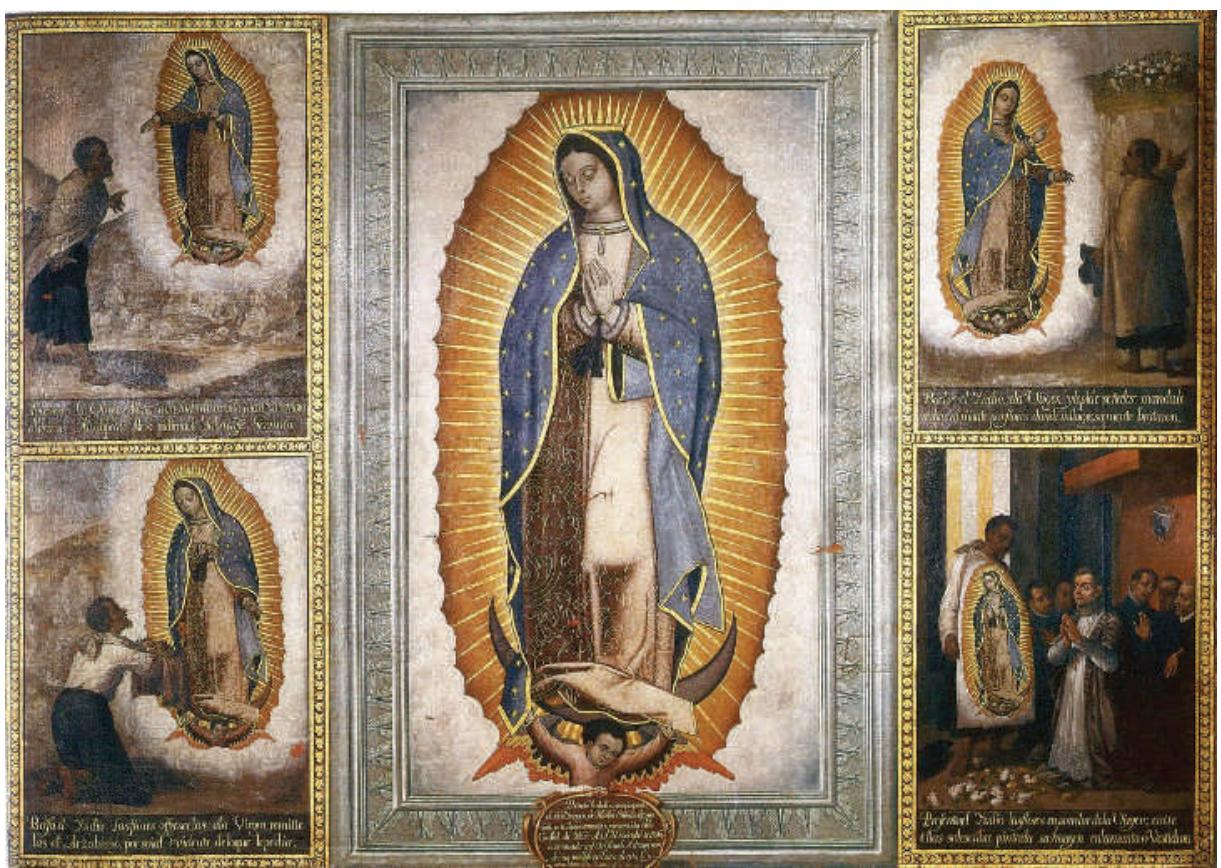

José Juárez. Virgen de Guadalupe con apariciones. Óleo sobre lienzo. Convento de la Concepción, Soria, 1656.

pística serial que emprende el pintor se basa en una idea ubicua de la fidelidad, donde el reconocimiento no basta: es necesaria la transmisión de un cierto mensaje. Dicha modalidad de reproducción, sin duda, tendrá influencia en lo que he denominado el cambio de la economía de proliferación, dado que la copística extrae definitivamente a la imagen de su medievalidad y su característico régimen de rarefacción: ya no es simple índice -ella misma "asentada" en palabras de Lasso-, sino revelación continua. La imagen se oculta en su tecnificación. Este es el sentido que adquirió a partir de las copias de Miguel Cabrera, y el que prevalecerá a lo largo del siglo posterior, donde las soluciones icónicas son la norma. Tal preeminencia de la solución icónica no es deningún modo una clausura, dado que las representaciones de la tilma serían usadas posteriormente, pero de manera adyacente, y en composiciones no devocionales, como se observa en la pintura de la declaración del patronato que hiciera Cabrera en el siglo XVIII.

Según afirma José Ibarra en un añadido a Maravilla Americana, en el texto de Miguel Cabrera sobre la imagen, Juan Correa habría hecho un calco con papel encerado de la imagen estampada en la tilma. Se trata de un gesto significativo que señala un cambio en la comprensión del objeto milagroso, donde lo importante es la imagen ("en sí") de la Virgen. No es el tratamiento dado a una antigüedad, sino a una "prodigiosa imagen”, en palabras de Cabrera. 
El gesto del calco consistiría, entonces, en la extracción con respecto a la imagen de toda cualidad objetual, una destilación del milagro que se extendería por contacto. Este modelo copístico que seguía un modelo netamente icónico, no excluye que se escribiera muchas veces sobre las pinturas - como en calidad de certificación -, que la imagen había sido "tocada al original" como se aprecia en la inscripción inferior de una pintura de José Juárez localizada en Agreda, y en muchas copias hasta el siglo XVIII. Este recurso se encuentra a medio camino entre los dos paradigmas, el de la representación y el de la copia.

Dos cosas sobre esta pintura de Juárez, fechada en 1656, que es importante discutir. En primer lugar, supone un precedente en el tratamiento de la imagen junto a los milagros narrados en el Nican, elementos que se volverán comunes en un gran número de composiciones hasta el siglo XIX. En segundo lugar, Juárez pinta la imagen de la virgen en el centro, separada del ayate, una virgen ideal, desmaterializada, que además ha sido tocada del original milagroso, por lo que su estatus devocional aumenta. Se trata de la adopción neta de la solución icónica, que abandona los remanentes materiales de la imagen, por lo que la pintura constituye la presentación misma de la virgen, aunque de manera derivativa.

Este proceso reproductivo (¿un caso anticipado de la "reproductibilidad técnica" estudiada por Benjamin?) de la imagen en México dio la posibilidad de un desdoblamiento constante; el reforzamiento de un "sentido oculto" sumado al recurso del contacto ("tocada a...") generó una tradición visual de una complejidad enorme que, sin duda, dio forma al culto que llega hasta nuestros días, y cuyas tecnologías visuales continúan evolucionando de maneras diversas. Parte de esta tradición es la producción de una enorme cantidad de exvotos, que no abordo porque este análisis pretende a estudiar la coherencia de una tradición visual que forma parte de un programa institucional. El estudio de la visualidad es un fenómeno complejo que debe partir de las jerarquías políticas que la regulan. Tal distinción es una clave para hacer un análisis fino de la cultura visual.

Pero es importante recalcar que la economía escópica ha cambiado: la mirada se ha dirigido hacia una imagen particular que ha sido como extraída de la representación, que no es una pintura de la virgen como se habría ensayado en pinturas tempranas del siglo XVI, sino que es la virgen estampada. El desdoblamiento de la imagen en el siglo xviII garantizó un culto uniforme, en el que las "casitas" de la virgen se multiplicaban también, y gracias a este proceso se construyeron las basílicas menores de Zacatecas y la de San Luis Potosí. De esta manera, se resuelve la tensión que caracteriza a las imágenes milagrosas: la incapacidad de superar el culto local y, en el extremo opuesto, la mutación en nuevos cultos locales al expandirse. La importancia de la visualidad parece ser fundamental en este proceso, y debe ser analizada en sus propias lógicas.

Es posible afirmar que las copias, desde finales del siglo xvin con Cabrera como máximo exponente, pasando por el siglo XIX, hasta nuestros días, se han mantenido 


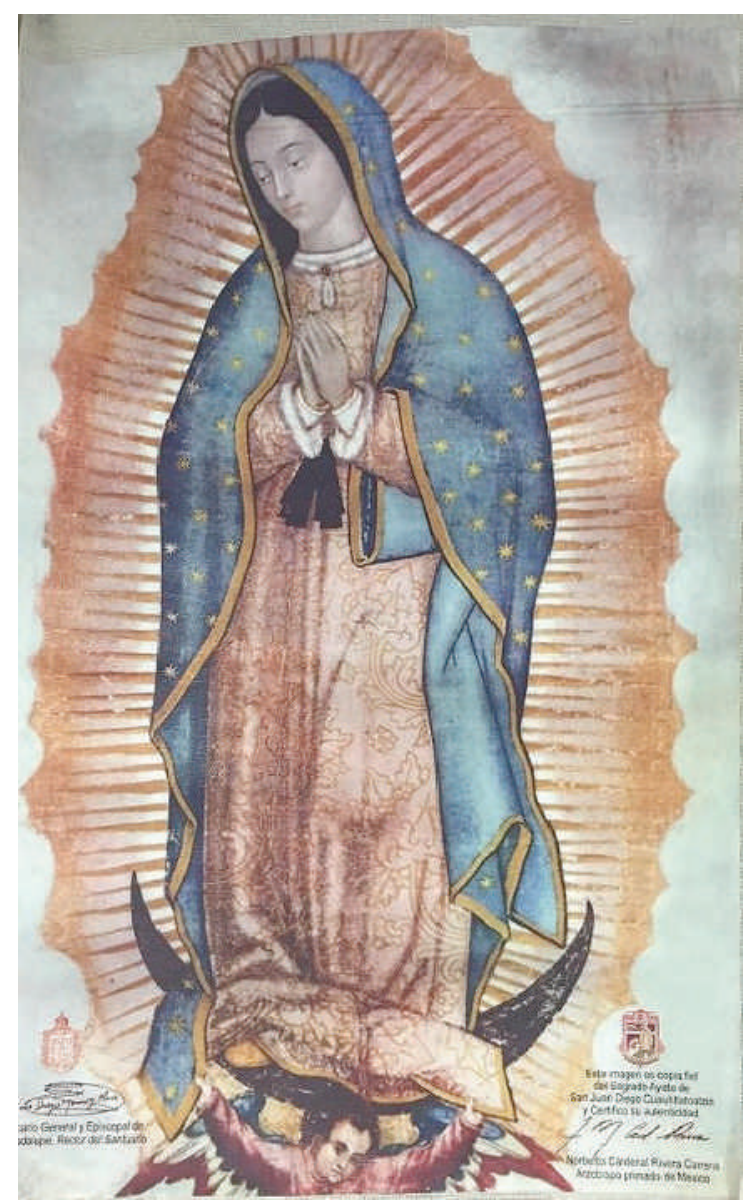

Anónimo. Litografía certificada de la Virgen de Guadalupe. Basílica de Guadalupe, México.

bajo el mismo régimen escópico. Cuando digo que las copias contemporáneas se ciñen al mismo régimen, hablo de las litografías certificadas, supuestamente de tamaño natural y de extraordinaria calidad, que distribuye la diócesis con propósitos devocionales. Al pie del lado izquierdo se encuentra la firma del Rector del Santuario y del lado derecho se encuentra la leyenda: "Esta imagen es copia fiel del Ayate de San Juan Diego Cuauhtlatoatzin y certifico su autenticidad" seguido de la firma identificada más abajo del Arzobispo primado de México, Norberto Cardenal Rivera Carrera.

El concepto de verdad que realzaba el interés por la pintura de José Juarez ("retrato verdadero") permanece en la autentificación autorizada por el arzobispo, quien prescinde, mediante la técnica fotográfica, de los artistas. Se trata ya de una superación de la copística tradicional que dependía de los previos elementos artísticos, mediante un recurso de replicación más depurado. Sin embargo, se mantiene la continuidad con la tendencia visual iniciada con la decantación sistemática por la solución icónica; de 
nuevo el ideal de propagación de la imagen, delineado desde el siglo XviI, se cumple en el siglo xx. No obstante, estos anacronismos visuales no dejan de tener su costo: la imagen se vuelve compulsiva, se distingue en todas partes y deja de dar forma a la cultura mexicana, para acecharla y perseguirla.

\section{Fenómenos viso-sociales}

El momento en que se trasladó la imagen a su nueva "casita" fue transmitido en vivo por televisión, modalidad que aporta un componente de novedad tecnológica al despliegue visual. Se diseñó para la ocasión un mecanismo que permitía su descenso y transportación para evitar que el elemento humano obstaculizara la exhibición de la imagen o que esta se balanceara demasiado (Martínez 240). De nuevo se trata de minimizar lo humano, como se hizo con las copias, pero ahora en la dimensión televisiva. De allí que la "transmisión del mensaje", según el modelo profético-tipológico de Sánchez, se haga literal. Las grabaciones de la empresa Televisa muestran cómo la Virgen asciende sin aparente apoyo a su nuevo altar en la Nueva Basílica, ahora mucho más elevado que el anterior.

No se trata solamente de una tradición más que pervive, un traslado más entre los muchos que padeció la imagen en los avatares de su historia, más bien refiere a que su sentido parece ser dirigido desde el pasado, dada la idealización y desmaterialización a la que tiende el tratamiento que se le dio a la imagen, sobre todo desde el siglo xviII. Proceso al que se le daría continuidad en el siglo xx, mediante la animación total de la imagen durante esta escena de apoteosis televisiva.

Pero no todos los momentos relacionados al guadalupanismo serían tan apoteóticos, incluso pudieron llegar al desastre y destrucción cultural. Así sucedió más recientemente con la obra del dibujante Manuel Ahumada, muerto en el 2014. Su dibujo La patrona, expuesto en el 2000 en el Museo del Periodismo y las Artes Gráficas de Guadalajara, fue destrozado por unos jóvenes ultracatólicos, a los que les parecía obsceno el tratamiento del tema "juandieguino". Sin embargo, ante estos hechos, la primera pregunta que debe hacerse es ¿se trata de una representación de San Juan Diego?

Escribía un periodista del periódico La Jornada que "si hay un indio, este debe necesariamente ser Juan Diego" (Velázquez Ramírez 2), señalando con sorna lo que debería ser evidente: la ausencia absoluta de la Virgen, a la que se supone aludiría el título por ser la "Patrona" de México y de América y, por lo tanto, la arbitrariedad en que consistiría afirmar que el personaje era Juan Diego. Se trata de un juego de inteligencia en el que los elementos iconográficos logran elidirse unos a otros y, por lo tanto, reina la ausencia en medio de la invocación.

Si el proceso de asunción de la Virgen -me refiero a la asunción literal de 1976- requiere una presencia absoluta -la omnipresencia-, quizá la mayor ofensa en un país que llegó a ser lo que es debido a esa presencia perfecta, sea la ausencia. 
FIGURA 11

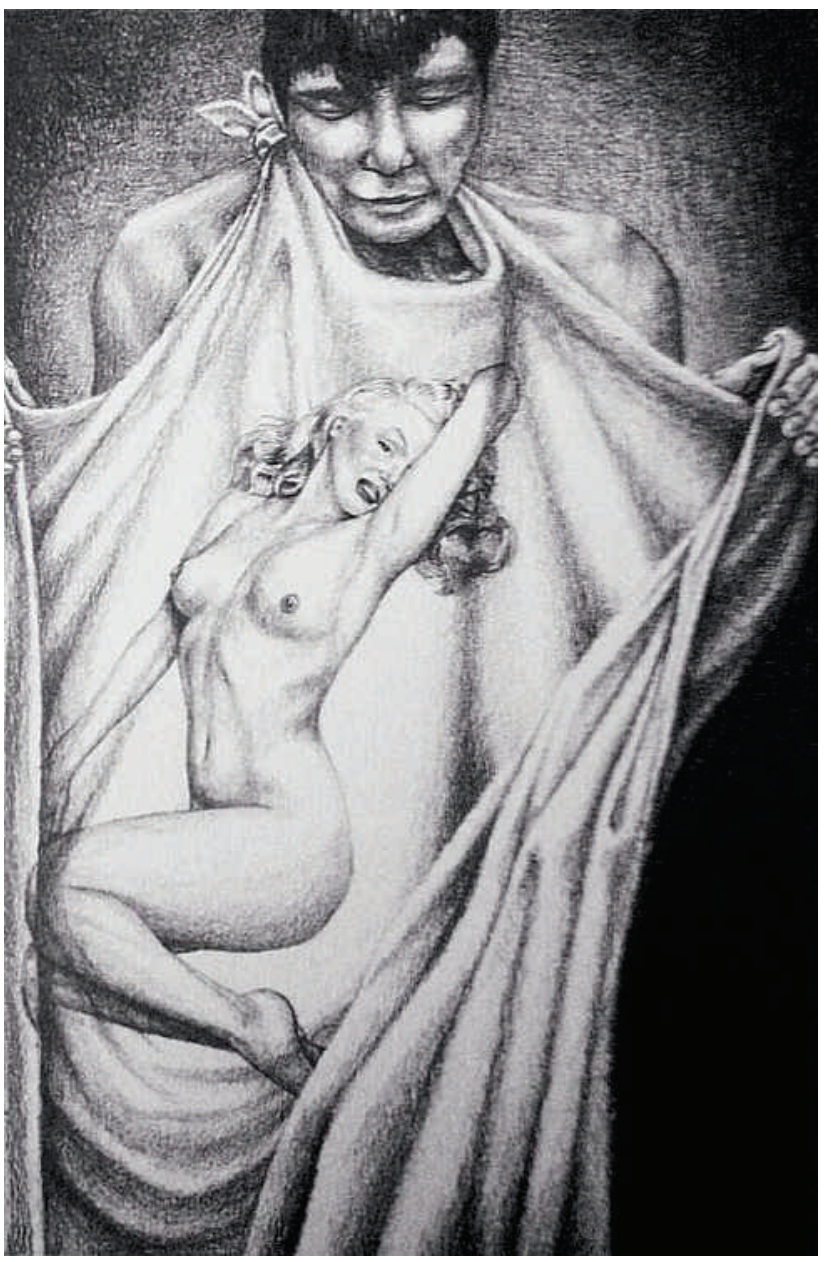

Manuel Ahumada. La patrona. Dibujo a lápiz destruido tras su exposición, Guadalajara, 2000.

Dibujar a la virgen sin que esté presente genera la contradicción visual misma, es un acto contestatario de lo más efectivo. Creo que el erotismo aparente de la imagen, y la ofensa que constituiría la sustitución de la imagen de la Virgen por la de Marilyn Monroe, se derivan de una ausencia absoluta que pone de manifiesto las tecnologías visuales y su consecuencia histórica: la construcción de una mirada que demanda la presencia del ícono protector. Es decir, que una historia de exposición a la imagen genera su necesaria recepción allí donde esta es imposible.

Este caso, además, deriva de la asociación del guadalupanismo con la cultura popular, ineludible bajo una economía escópica de proliferación, en que la imagen es desplegada con enorme éxito en la cultura mexicana; pero, al mismo tiempo, apropiada y transformada de formas diversas. En estas condiciones es difícil controlar los significados y asociaciones que se le pueden atribuir, a no ser por medio de la violencia. 


\section{Conclusiones}

La relación de lo visual y lo social es ineludible y compleja. Lo social se construye a partir de lo visual y viceversa, como ha señalado Mitchell (Moxey 19). La historia del guadalupanismo, bajo este enfoque, aún está por hacerse. Deben desentramarse los engarces de esta historia que al final revela cierta manera de ver y, por lo tanto, un canal importante de recepción y construcción de un gran número de los significados (y vacíos) sociales en México. El presente ensayo es un recorrido muy somero por los recursos que constituyen una imagen a partir de una simbólica y, de este modo, pasa a ser fundamental en la construcción de una sociedad determinada. El procedimiento y la conceptualización pueden ser discutidos, pero las continuidades en las tecnologías visuales y los hechos sociales relacionados no pueden negarse.

Los conceptos visuales utilizados permiten una comprensión distinta del fenómeno guadalupano y sus alcances. Una tecnología visual y un régimen escópico son conceptos que pueden ayudar a vincular los Estudios Sociales con la Historia del Arte. El caso del guadalupanismo es elocuente al respecto: al tratarse de un sistema de equilibrios en donde la economía de rarefacción tiende al control de significados que serán experimentados por los artistas y, por tanto, por la sociedad, mientras que la proliferación facilitaría asociaciones y horizontes imprevistos.

Esta revisión coloca asímismo en el centro el papel de la experimentación visual para consolidar las formas en que se entendió la imagen. Por un lado, fue probada la representación de la antigüedad junto con la solución icónica, y fue esta última la más afín a las definiciones teológicas que relanzaron el culto, volviéndose el principal exponente de esta concepción Miguel Sánchez. Este último, reforzó el triunfo de las soluciones icónicas, limitando la representación de la antigüedad a ciertos casos especiales, alegóricos, conmemorativos o pedagógicos. En este caso, la relación entre el pensamiento visual y el teórico definen la posibilidad de expansión de la imagen.

\section{Referencias}

Bargellini, Clara. "Originality and invention in the painting of the New Spain”. Painting a New World. Mexican Art and life. 1521-1821. Denver, University of Texas Press, 2004, pp. 79-90.

Cabrera, Miguel. Maravilla americana y conjunto de raras maravillas observadas con la dirección de las reglas del arte de la pintura en la prodigiosa imagen de Nuestra Sra. de Guadalupe de México. México, Imprenta Real y Colegio de San Ildefonso, 1756.

Camacho de la Torre, María Cristina. Fiesta de nuestra señora de Guadalupe. Celebración, historia y tradición mexicana. México, ConACLTA, 2001. 
Cuadriello, Jaime. "El discurso de la ceremonia de jura: un estatuto visual para el reino de Nueva España El caso del Patronato Guadalupano de 1746". Tiempos de América, n², 1998, pp. 3-18.

Cuesta Hernández, Luis Javier. "La mayor fábrica que en este tiempo se ha ofrecido que es la de la iglesia de Nuestra Señora de Guadalupe. La construcción del templo. Algunas cuestiones". Tres siglos en el Tepeyac. El antiguo templo y morada de Guadalupe (1709-2009). México, Museo de la Basílica de Guadalupe, 2009, pp. 101-133.

De Florencia, Francisco. Zodiaco mariano. México, CNCA, 2001.

De la Maza, Francisco. El guadalupanismo mexicano. México, FCE, 1981.

Fumaroli, Marc. "Apologética de las imágenes sagradas". Artes de México, nº 70, pp. 17-37.

Gruzinski, Serge. La guerra de las imágenes. De Cristobal Colón a"Blade Runner" (1492-2019). México, FCE, 1994.

Jay, Martin. Campos de fuerza. Entre la historia intelectual y la crítica cultural. Buenos Aires, Paidós, 2007.

---. “¿Parresía visual? Foucault y la verdad de la mirada”. Estudios Visuales, nº 4, 2007, pp. 8-21.

Velázquez Ramírez, Juan Manuel. "Manuel Ahumada, in memoriam: el caso de La Patrona y la guerra desde la imagen". La Jornada Jalisco, 8 de enero 2014, s.p.

Lasso de la Vega, Luis. Huei tlamahuzoltica. México, Carreño e Hijo, 1926.

León-Portilla, Miguel. Tonantzin Guadalupe. Pensamiento náhuatl y mensaje cristiano en el "Nican Mopohua". México DF, COLmex, 2010.

---, traductor. "Nican Mopohua". Juan Diego Cuauhtlatoatzin. España, Museo de la Basílica de Guadalupe, 2005.

Martínez, Iván. "Los estrenos de una casa. Los templos y fiestas a Guadalupe". Tres siglos en el Tepeyac. El antiguo templo y morada de Guadalupe (1709-2009). México, Museo de la Basílica de Guadalupe, 2009, pp. 177-245.

Moxey, Keith. "Los estudios visuales y el giro icónico". Estudios visuales, n 6, 2009, pp. 8-28.

Sánchez, Miguel. Imagen de la Virgen María Madre de Dios de Guadalupe. México, Imprenta de la Viuda de Bernardo Calderos, 1648.

Toussaint, Manuel. Pintura Colonial en México. México, unam, 1999.

Vargas Lugo, Elisa. "Algunas notas más sobre iconografía guadalupana". Anales del Instituto de Investigaciones Estéticas, 1989, pp. 59-66.

Recibido: 28 junio 2017 